\title{
Translation and cross cultural adaptation of the Pediatric Motor Activity Log-Revised scale
}

\author{
Tradução e adaptação transcultural da escala Pediatric Motor Activity Log-Revised \\ Gabriela da Silva Matuti', Juliana Firmo dos Santos', Ana Carolina Rodrigues da Silva ${ }^{1,2}$, Rafael Eras-Garcia', \\ Gitendra Uswatte ${ }^{3,4}$, Edward Taub ${ }^{3,4}$
}

\begin{abstract}
The standardized instrument developed to assess the use of the affected upper limb in children with cerebral palsy (CP) is the Pediatric Motor Activity Log Revised (PMAL-R). Objectives: To translate PMAL-R and adapt for the Brazilian culture; analyze the reliability and the internal consistency of the Brazilian version. Method: Translation of PMAL-R to the Portuguese-Brazil and back translation. The back-translated version was revised by the authors of the scale. The final version was administered to a sample of 24 patients with spastic hemiparesis $\mathrm{CP}$ between 2-8years. Results: The reliability intra and inter-rater were suitable (how often $=0.97$ and 0.98 , how well $=0.98$ and 0.99 respectively) and so the internal consistency (0.98). Conclusion: The Brazilian version of PMAL-R has adequate internal consistency, reliability intra and inter raters and can be used to assess the spontaneous use of the upper limb of children with CP type spastic hemiparesis, aged 2-8 years.
\end{abstract}

Keywords: cerebral palsy; upper extremity; activities of daily living; evaluation.

\section{RESUMO}

A Pediatric Motor Activity Log-Revised (PMAL-R) é um instrumento padronizado desenvolvido para avaliar o uso do membro superior afetado em crianças com paralisia cerebral (PC). Objetivos: Traduzir a PMAL-R e fazer sua adaptação transcultural para o Português do Brasil; analisar a confiabilidade e a consistência interna da versão brasileira. Métodos: Tradução e retrotradução da PMAL-R. A versão retrotraduzida foi revista pelos autores da escala; a versão final foi administrada a uma amostra de 24 pacientes com PC do tipo hemiparesia espástica entre 2-8 anos. Resultados: Adequada confiabilidade intra e inter-avaliadores (frequência $=0,97$ e 0,98, qualidade $=0,98$ e 0,99, respectivamente), assim como a consistência interna (0,98). Conclusão: A versão brasileira da PMAL-R apresenta consistência interna e confiabilidade intra e inter examinadores adequadas, sendo válida para avaliar o uso espontâneo do membro superior de crianças com PC do tipo hemiparesia espástica, com idade entre 2-8 anos.

Palavras-chave: paralisia cerebral; extremidade superior; atividades cotidianas; avaliação.

Cerebral palsy (CP) describes a group of disorders of movement and posture that are attributed to a non-progressive disorder in the immature brain and often limit functional activities ${ }^{1}$.

Children with spastic hemiplegia, which is one type of CP, can experience difficulty in using the affected upper limb (AUL) - the limb contralateral to the lesion - because of poor selective motor control, muscle weakness, a stereotyped posture, and sensory deficits. These difficulties make attempts to use the AUL less frequent, and favor compensatory strategies in which the unaffected limb is used to perform functional activities. This can culminate in a cycle that results in decreased cortical representation of the affected segment because of disuse, thus developing the phenomenon known as "learned nonuse".
Traditionally, the functionality of the AUL has been evaluated by observing motor performance during tests conducted in the clinic. However, the use of the AUL in this context often fails to reflect how the child actually performs in the real world ${ }^{3,4}$. The relationship between performance assessed by tests in the clinic environment and the spontaneous use of the AUL outside the therapeutic setting has not been established. Clinic-based tests do not take into consideration the phenomenon of learned nonuse, and therefore the effects of rehabilitation on everyday function are not properly evaluated ${ }^{3,4}$.

A standardized instrument developed specifically to evaluate the function and spontaneous use of the AUL in children aged 2-8 years with CP is the Pediatric Motor Activity Log

${ }^{1}$ Associação de Assistência à Criança Deficiente (AACD), Grupo de Pesquisa em Terapia de Contensão Induzida (TCI), São Paulo SP, Brasil;

${ }^{2}$ Universidade Federal de São Paulo, Ciências da Saúde, São Paulo SP, Brasil;

${ }^{3}$ University of Alabama at Birmingham, Constraint Induced Therapy (CIT) Research Group, Alabama, USA;

${ }^{4}$ University of Alabama at Birmingham, Psychology Department, Alabama, USA.

Correspondence: Gabriela da Silva Matuti; Rua Lourdes Lopes Sanches, 300; 07190-033 Guarulhos SP, Brasil; E-mail: gabrielamatuti@hotmail.com

Conflict of interest: There is no conflict of interest to declare.

Received 02 October 2015; Received in final form 18 December 2015; Accepted 16 May 2016. 
(PMAL) $)^{5,6}$. Taub and co-workers adapted the PMAL in 2004 from the Motor Activity Log, which was developed for adult patients who had experienced a stroke. ${ }^{6}$ The protocol of the PMAL is the same as for the adult Motor Activity Log, except for three departures: (1) the point of reference for evaluating the function of the more-affected arm is the less-affected arm, rather than the same arm before brain injury; (2) on items that can include a wide variety of tasks, such as Item 17 ("push large object across floor"), the tester notes the particular activity assessed when administering the test for the first time, and asks about that specific activity on subsequent administrations; and (3) the primary caregivers of the child being treated are questioned, rather than the patient him/herself?

The PMAL is administered as a structured interview that is completed by the child's parents or caregivers. Respondents rate "how often" (HO) and "how well" (HW) the AUL is moved in 22 different activities. Both subscales range from 0 to 5 : on the HO subscale, $0=$ no use, $1=$ too rarely, $2=$ rarely, $3=$ sometimes, $4=$ often, and $5=$ normal; and on the HW subscale, $0=$ no use, $1=$ very poor, $2=$ poor, $3=$ moderate, $4=$ almost normal, and $5=$ normal. $^{7}$ The PMAL is an important tool for evaluating children with $\mathrm{CP}$ because the functional activities reflect the neurologic and psychomotor acquisitions expected for the age group, and the tool contains a variety of bimanual, unimanual, basic, and instrumental activities that are performed in the real world (i.e., outside the therapeutic setting) ${ }^{7}$.

In 2012, Uswatte et al. analyzed the test-retest reliability and convergent validity of a revised version of the PMAL, the PMAL-R, in children with CP with upper-extremity hemiparesis. The study examined a sample of 60 children aged 2-8 years old, and the PMAL-R showed good test-retest reliability $(r=0.89)$ and internal consistency (Cronbach's alpha $=0.93$ ), with convergent validation supported by a strong correlation between the PMAL-Rand spontaneous use of the AUL on the Pediatric Arm Function Test $(r[53]=0.5, \mathrm{p}<0.01)$. Therefore, the PMAL-R is a suitable test for this population?

There are no instruments developed or adapted for Brazilian Portuguese to assess the function and spontaneous use of the AUL outside the therapeutic environment for children with spastic hemiparesis. Therefore, the purposes of this study were to translate and cross-culturally adapt the PMAL-R, and to analyze the reliability and internal consistency of this Brazilian Portuguese adaptation.

\section{METHOD}

The study design was submitted to and approved by the Ethics Commission of the Associação de Assistência à Criança Deficiente, São Paulo, Brazil (authorization no. 14182118).

Participants were recruited according to the following inclusion and exclusion criteria.

Inclusion criteria were: (1) a diagnosis of $\mathrm{CP}$ with spastic hemiparesis; (2) ages 2-8 years; (3) presence of an active range of motion of the AUL, according to the grade table (Table 1$)^{8}$; (4) parent or caregiver with adequate cognition (able to understand a numeric score) and who could complete the questionnaire on two separate occasions; and (5) parent or caregiver agreement and signed consent. Data were excluded if the parent or caregiver did not complete the questionnaire on two occasions.

\section{Translation of the instrument}

The PMAL-R was translated into Brazilian Portuguese by two bilingual translators whose native language was Portuguese. Translations were performed independently to obtain a more appropriate translated version ${ }^{9,10}$. The researchers then analyzed the two translated versions and the original English version and participated in a comparative discussion in order to obtain a single, final version in the Portuguese language (version consensus, Version 1 [V1]).

V1 was back-translated by two further qualified translators, whose original language was English (the language of the original instrument) and who had no prior knowledge of the intent or concepts of the material. The back-translators performed this process independently. The back-translations were then subjected to a comparative analysis among the researchers regarding the two back-translated versions and the original, to obtain a single, final version in English language (version consensus, Version 2 [V2]).

V2 was sent to the original authors of the PMAL-R for correction. The authors did not change any items in this version, but made some suggestions on how to apply one item (pointing a figure - the authors recommended that it was in a book).

\section{Semantic analysis by a judging committee}

According to Pasquali, the aim of this step is to assess whether the terms used in the items are understandable, and whether they are suitable for the population under evaluation with respect to the motor activities performed by this age group ${ }^{11}$. To this end, two groups were selected: 15 judges from a low stratum (i.e., people from the field of physical rehabilitation who were unaware of the PMAL-R) and 15 from a high stratum (i.e., people in the field of pediatric physical rehabilitation with prior knowledge of the original PMAL-R $)^{11}$. Items that were understood by fewer than $80 \%$ of participants $\left(\frac{U}{U+N U} X 100\right)$ (where $\mathrm{U}$ is the number of items that were understandable by the lower stratum and $\mathrm{NU}$ is the number of items that were not understandable) were candidates for cross-cultural adaptation. The lower stratum, in this case, represented the target population (i.e., parents or caregivers) with no knowledge of the PMAL- ${ }^{12}$.

Although the original authors of the PMAL-R were not asked to correct V1 (i.e., PMAL-R Brazilian Portuguese) it was subjected to semantic analysis by the judging committee, who discussed the clarity of the translated items and the relevance of the instrument to the population for which it was intended (i.e., low stratum) and its clinical relevance (i.e., high stratum). 
Table 1. University Alabama at Birmingham (UAB) Constraint Induced Therapy (CIT) Research Group Grade Table - Active Range of Motion.

\begin{tabular}{|c|c|c|c|c|c|}
\hline & Shoulder & Elbow & Wrist & Fingers & Thumb \\
\hline Grade 2 & $\begin{array}{l}\text { Flexion \& Abduction } \\
\quad \geq 45^{\circ}\end{array}$ & $\begin{array}{l}\text { Extension } \geq 20^{\circ} \text { from } \\
\text { a } 90^{\circ} \text { flexed starting } \\
\text { position }\end{array}$ & Extension $\geq 20^{\circ}$ & $\begin{array}{l}\text { Extension of all MCP and } \\
\text { IP (either PIP or DIP) joints } \\
\geq 10^{\circ} \text {; may be assessed by } \\
\text { attempting to pick up and } \\
\text { drop tennis ball }\end{array}$ & $\begin{array}{l}\text { Extension or } \\
\text { abduction of } \\
\text { thumb } \geq 10^{\circ}\end{array}$ \\
\hline Grade 3 & $\begin{array}{l}\text { Flexion \& Abduction } \\
\quad \geq 45^{\circ}\end{array}$ & $\begin{array}{l}\text { Extension } \geq 20^{\circ} \text { from } \\
\text { a } 90^{\circ} \text { flexed starting } \\
\text { position }\end{array}$ & Extension $\geq 10^{\circ}$ & $\begin{array}{c}\text { Extension of MCP and IP } \\
\text { (either PIP or DIP) joints } \\
\text { of at least } 2 \text { fingers } \geq 10^{\circ} \text {; } \\
\text { may be assessed by } \\
\text { attempting to pick up and } \\
\text { drop a washcloth }\end{array}$ & $\begin{array}{l}\text { Extension or } \\
\text { abduction of } \\
\text { thumb } \geq 10^{\circ}\end{array}$ \\
\hline Grade 4 & $\begin{array}{l}\text { Flexion \& Abduction } \\
\quad \geq 45^{\circ}\end{array}$ & $\begin{array}{l}\text { Extension } \geq 20^{\circ} \text { from } \\
\text { a } 90^{\circ} \text { flexed starting } \\
\text { position }\end{array}$ & Extension $\geq 10^{\circ}$ & $\begin{array}{l}\text { Extension of at least } 2 \\
\text { fingers }>0^{\circ} \text { and }<10^{\circ} ; \\
\text { may be assessed by } \\
\text { attempting to pick up and } \\
\text { drop a washcloth }\end{array}$ & $\begin{array}{l}\text { Extension or } \\
\text { abduction of } \\
\text { thumb } \geq 10^{\circ}\end{array}$ \\
\hline \multicolumn{6}{|l|}{ Grade 5} \\
\hline Subclass A & $\begin{array}{l}\text { Flexion, abduction, or } \\
\text { scaption } \geq 30^{\circ}\end{array}$ & $\begin{array}{l}\text { Initiate extension \& } \\
\text { flexion at the elbow }\end{array}$ & \multicolumn{3}{|c|}{$\begin{array}{l}\text { Must be able to either initiate extension of the wrist or initiate } \\
\text { extension of any digit. } \\
\text { Maximal Motor Criteria: wrist extension }>10^{\circ} \text {, thumb abduction }>10^{\circ} \text {, } \\
\text { and initiate extension of at least } 2 \text { additional digits }\end{array}$} \\
\hline Subclass B & $\begin{array}{l}\text { Flexion, abduction, or } \\
\text { scaption } \geq 30^{\circ}\end{array}$ & $\begin{array}{l}\text { Extension } \geq 20^{\circ} \text { from } \\
\text { a } 90^{\circ} \text { flexed starting } \\
\text { position. }\end{array}$ & \multicolumn{3}{|c|}{$\begin{array}{l}\text { No active movement required for the wrist, fingers, or thumb. } \\
\text { Maximal Motor Criteria: wrist extension }>10^{\circ} \text {, thumb abduction }>10^{\circ} \text {, } \\
\text { and initiate extension of at least } 2 \text { additional digits }\end{array}$} \\
\hline
\end{tabular}

Note: Each movement should be repeated 3 times in 1 minute in order to meet criteria. Grade 1 movement designates a patient that has normal or near normal active range of motion. MCP: metacarpophalangeal; PIP: proximal interphalangeal, DIP: distal interphalangeal.

\section{Inter- and intra-rater reliability}

V1 was submitted for analysis by the committee of judges and changed based on their suggestions; the final version was called the PMAL-R Brazil. The PMAL-R was tested in a population of 24 caregivers to analyze its clinimetric properties (intra- and inter-rater reliability, and internal consistency). The sample size was selected according Terwee and colleagues, who suggested that a sample of 4-10 subjects should be screened for each variable ${ }^{13}$, and taking into account that the PMAL-R has two variables (HO and $\mathrm{HW}$ ).

Each parent or caregiver underwent two identical PMAL-R Brazil interviews conducted by two different evaluators (A and B) on the same day, with 40 minutes between each interview. After 7 days, the PMAL-R Brazil was repeated with each caregiver, with the interview conducted by evaluator A only ${ }^{7,14,15}$. Each evaluator had been trained at the University of Alabama at Birmingham (AL, USA) and followed the manual for the original PMAL- $\mathrm{R}^{7,15}$. All participants signed a consent form.

Each caregiver was first given an introduction regarding the purpose of the evaluation and instructions on how to answer the questions. The evaluators then asked the caregivers about how often and how well their child used the AUL to perform the tasks listed in the PMAL-R Brazil, with reference to the previous week.

\section{Statistical analysis}

The normality of the data was tested and confirmed using the Kolmogorov-Smirnov test, and data are presented as mean \pm standard deviation. Descriptive statistical analysis was used for demographic and clinical characterization of the patients. The paired Student $t$ test was used to compare the two dependent samples. The intraclass correlation coefficient (ICC) was used to measure reliability, and is presented with a $95 \%$ confidence interval. For the ICC, reliability was characterized as good (score $0.80-1.0$ ), moderate $(0.60-0.79)$, or poor $(<0.60)$. Cronbach's alpha was used to evaluate the internal consistency of the PMAL-R Brazil. SPSS 19.0 (Chicago, IL, USA) was used for statistical analysis ${ }^{16,17,18}$.

\section{RESULTS}

The demographic characteristics of the sample $(\mathrm{N}=24)$ are described in Table 2.

In the semantic analysis, the committee of judges asked questions about the meaning of four of the items. Although Item 6 ("passing his arm through the sleeve of a garment") was understood by all judges in the high stratum, it was not 
understood by nine participants in the low stratum. This was mainly due to the formulation of the question, which was not specific about the length of the sleeve (Table 3). Three participants in the high stratum and nine in the low stratum were confused by Item 18 ("holding a small ball"), in particular about the size of the ball. For Item 19 ("throwing a ball or other object"), three participants of the low stratum asked about the size of the object to be thrown. For Item 20 ("using a cylindrical object-a pen, pencil, or crayon"), only one participant, in the high stratum, pointed to the word "cylindrical" as a possible generator of doubt, and suggested the use of examples that were already in the question (Table 3).

With regard to the suitability of the items for the age group being tested, only Item 14 ("Use the arm to move down - drag, crawl") was scored as not suitable (by five participants in the high stratum). They reported that the target population (children aged 2-8 years old with hemiparesis) did not realize that this activity was intended to be ambulatory.

Both intra-rater reliability (with a mean interval of 7 days) and inter-rater reliability were excellent (ICC $=0.97-0.98$ and 0.98-0.99, respectively) (Table 4). Internal consistency was

Table 2. Demographic characteristics of patients evaluated for reliability study (mean \pm standard deviation).

\begin{tabular}{|c|c|}
\hline Variable & Patients $(n=24)$ \\
\hline Age (years) & $5.0 \pm 1.7$ \\
\hline Age (months) & $66.2 \pm 20.6$ \\
\hline \multicolumn{2}{|l|}{ Gender n (\%) } \\
\hline Male & $10(41.7)$ \\
\hline Female & $14(58.3)$ \\
\hline \multicolumn{2}{|c|}{ Topographic diagnosis } \\
\hline Left & $14(58.3)$ \\
\hline Right & $10(41.7)$ \\
\hline \multicolumn{2}{|c|}{ Motor degrees n (\%) } \\
\hline 2 & $12(50)$ \\
\hline 3 & $12(50)$ \\
\hline
\end{tabular}

also excellent (Cronbach's alpha $=0.97$ for the HO subscale and 0.98 for the HW subscale).

\section{DISCUSSION}

The World Health Organization recommends the translation and cross-cultural adaptation of existing instruments of evaluation, because this improves communication between researchers and permits comparison of data obtained internationally ${ }^{9,12}$. Furthermore, the use of validated instruments increases confidence in the measurements obtained ${ }^{9}$.

When adapting an instrument to a new country or culture, it is important to use a method that maintains equivalence between the original and translated versions, while at the same time making any cross-cultural adaptations required. Furthermore, the psychometric properties of the adapted instrument must be tested ${ }^{9,12}$.

The PMAL-R assesses the functional use of the AUL in the real world, and is conducted via a structured interview using an evaluation script. This tool has demonstrated good stability, reliability, and validity ${ }^{5,7}$.

In 2013, Rickards et al. conducted a study to identify the relationship between white-matter integrity and the corticospinal path in AUL function before and after constraint-induced movement therapy (CIMT) in children with CP with spastic hemiparesis. The authors observed a significant association between fractional anisotropy values of the corticospinal tract and pretreatment spinal motor function, with similar findings in relation to the PMAL-R. Patients with more lesions in the corticospinal path (resulting in disruption or dysplasia) showed worse results on the pretreatment PMAL-R compared with patients without lesions, indicating that the PMAL-R was sensitive enough to identify a clinical alteration that correlated with structural change ${ }^{19}$.

Also in 2013, Sterling et al. conducted a piece of research that aimed to compare demonstrated gains in motor and

Table 3. Terminology questions, percentage of non-understandable items and suggestions.

\begin{tabular}{|c|c|c|c|}
\hline \multirow{2}{*}{$\begin{array}{l}\text { Questioned terminology } \\
\text { (understandable / not understandable) }\end{array}$} & \multicolumn{2}{|c|}{ Percentage of not understandable (NU\%) } & \multirow{2}{*}{ Suggestions } \\
\hline & High stratum & Low stratum & \\
\hline 6. Put arm through sleeve of garment & $0(0)$ & $9(60)$ & $\begin{array}{l}\text { Wear a shirt, put the arm } \\
\text { inside the shirt sleeve, } \\
\text { dressing the arm through the } \\
\text { sleeve of a shirt. }\end{array}$ \\
\hline 18. Hold a small ball & $3(20)$ & $9(60)$ & $\begin{array}{l}\text { Holding a small ball with one } \\
\text { hand, holding a ping-pong } \\
\text { ball (or the same size). }\end{array}$ \\
\hline 19. Throwing a ball or a small object & $0(0)$ & $3(20)$ & $\begin{array}{l}\text { Size of the ball, give an } \\
\text { example. }\end{array}$ \\
\hline $\begin{array}{l}\text { 20. Use a cylindrical object (e.g., } \\
\text { highlighter, crayons) }\end{array}$ & $1(7)$ & $0(0)$ & $\begin{array}{c}\text { Cylindrical word, should give } \\
\text { an example. }\end{array}$ \\
\hline
\end{tabular}


Table 4. Intra e Inter rater reliability.

\begin{tabular}{cccc}
\hline Variable & ICC & $\begin{array}{c}\text { Confidence } \\
\text { interval (95\%) }\end{array}$ & p \\
\hline Intra rater reliability & & & \\
HO & 0.97 & $(0.94-0.99)$ & $<0.0001$ \\
HW & 0.98 & $(0.96-0.99)$ & $<0.0001$ \\
Inter rater reliability & & & \\
HO & 0.98 & $(0.97-0.99)$ & $<0.0001$ \\
HW & 0.997 & $(0.994-0.999)$ & $<0.0001$ \\
\hline
\end{tabular}

ICC: intraclass correlation coefficient; p: significance level; HO: how often; HW: how well.

functional evaluations with changes in brain gray matter using functional magnetic resonance imaging. The study showed that brain structural changes were largely accompanied by changes in the spontaneous use of the AUL in real life, as measured with the PMAL- ${ }^{20}$.

In the current study, the PMAL-R underwent the translation steps ${ }^{9}$ described above. In addition, an analysis of the linguistic and conceptual equivalence (semantic analysis) of the items was conducted. The conceptual equivalence is analyzed considering the translated term is relevant according to the culture in which the instrument is applied (appropriate or not appropriate). Linguistic equivalence (semantics) involves verifying whether the questions have kept the same meaning in the translation as in the original language, as well as ensuring that the words and terminology are clear, and that the sentences can be easily understood ${ }^{11,14}$.

The semantic analysis tested the language from the point of view of two different groups (i.e., high and low strata). The high stratum included rehabilitation professionals with experience in pediatric neurology and who had been trained in the application of the questionnaire in its original English version. The low stratum aimed to verify whether the items would be understood by the target population (parents and/or caregivers), and was composed of rehabilitation professionals who had no experience in pediatric neurology and no previous contact with the PMAL-R.

The analysis determined that of the 22 questions in the PMAL-R Brazil, the terminology of four was questioned by the reviewers. The items selected for change were Item 6 ("passing his arm through the sleeve of a garment") and Item 18 ("holding a small ball"), because these were understood by only $40 \%$ of the low stratum. We changed Item 6 to "put his arm through the sleeve of a T-shirt" because this reflected the motor activity desired in the item; the score was considered to be normal when the child performed a full elbow extension to wear the T-shirt.

The terminology of Item 18 was not changed. An example suggested by the lower stratum and the authors of the PMAL-R was that the size of the ball should be equal to a ping-pong ball, with this already exemplified in the question:"Holding a small ball, the size of a ping-pong ball."

With respect to the suitability of the questions for the age of the patients, only Item 14 ("use the arm to move down - drag, crawl”) was felt to be inadequate. This question was deemed to be suitable by only $67 \%$ of the high stratum. They reported that the target audience (patients aged 2-8 years with hemiparesis) would not attempt this activity because they were already ambulating. In 2004, Tieman and colleagues analyzed the motor skills of patients with CP using the Gross Motor Function Classification System and found that only $1-2 \%$ of individuals in grades I and II (similar to the present study sample) crawled in the evaluation, because they already walk ${ }^{21}$. Therefore, this item was discussed with the original authors of the PMAL-R and replaced with "use the arm to move on the ground - drag or crawl to grab objects underneath the furniture."

Studies of CIMT in children aged 2-8 years have demonstrated that children can acquire new motor programs after such therapy. In younger children (around 2 years), it has been demonstrated that crawling (a motor activity that is unusual for children with hemiparesis) can be acquired after CIMT, and is incorporated into the lives of these patients both as displacement and to explore the environment ${ }^{22,23}$.

In the current study, there were no statistical differences in the mean scores on the two domains of the PMAL-R Brazil between two interviews conducted with the same rater on the same day, with two different examiners. The PMAL-R Brazil also demonstrated excellent internal consistency.

The function of an individual can be measured using the International Classification of Functioning, Disability and Health (ICF), which is divided into three areas: body structure, activity, and participation. The activity domain is subdivided into a capacity assessment, which shows what the individual can do, and a performance evaluation, which looks at what the individual actually does on a day-to-day basis, at home and in the community. Despite this, most assessments for children with $\mathrm{CP}$ are limited with respect to the evaluation of performance by being performed in a controlled environment; although ability of the child is measured, this does not reflect the performance of the child outside the therapeutic environment ${ }^{21,24}$.

The current results suggest that the PMAL-R Brazil can be included in routine AUL assessments of patients with $\mathrm{CP}$. The PMAL-R Brazil is a reliable way to evaluate the performance of these individuals and thus meet the demands of the ICF.

In conclusion, this study has demonstrated the reliability of the Brazilian version of the PMAL-R. Through our analysis of reproducibility and internal consistency, we can conclude that the PMAL-R Brazil is appropriate for the routine assessment of the AUL of patients with $\mathrm{CP}$ with spastic hemiparesis aged 2-8 years old. 
1. Rosenbaum P, Paneth N, Leviton A, Goldstein M, Bax M, Damiano D. A report: definition and classification of cerebral palsy April 2006. Dev Med Child Neurol. 2006;49(Suppl 109):8-14. doi:10.1111/j.1469-8749.2007.tb12610.x

2. Hoare BJ, Imms C, Rawicki HB, Carey L. Modified constraint-induced movement therapy or bimanual occupational therapy following injection of Botulinum toxin-A to improve bimanual performance in young children with hemiplegic cerebral palsy: a randomised controlled trial methods paper. BMC Neurol. 2010;10(1):58. doi:10.1186/1471-2377-10-58

3. Saliba VA, Magalhães LC, Faria CDCM, Laurentino GEC, Cassiano JG, Teixeira-Salmela LF. [Cross-cultural adaptation and analysis of the psychometric properties of the Brazilian version of the Motor Activity Log]. Rev Panam Salud Publica. 2011;30(3):262-71. Portuguese. doi:10.1590/S1020-49892011000900011

4. Morris DM, Taub E, Mark VW. Constraint-induced movement therapy: characterizing the intervention protocol. Eura Medicophys. 2006;42(3):257-68.

5. Wallen M, Bundy A, Pont K, Ziviani J. Psychometric properties of the Pediatric Motor Activity Log used for children with cerebral palsy. Dev Med Child Neurol. 2009;51(3):200-8. doi:10.1111/j.1469-8749.2008.03157.x

6. Taub E, Ramey SL, DeLuca S, Echols K. Efficacy of constraint-induced movement therapy for children with cerebral palsy with asymmetric motor impairment. Pediatrics. 2004;113(2):305-12. doi:10.1542/peds.113.2.305

7. Uswatte G, Taub E, Griffin A, Vogtle L, Rowe J, Barman J. The pediatric motor activity log-revised: assessing real-world arm use in children with cerebral palsy. Rehabil Psychol. 2012;57(2):149-58. doi:10.1037/a0028516

8. Taub E, Uswatte G, Mark VW, Morris DM, Barman J, Bowman MH et al. Method for enhancing real-world use of a more affected arm in chronic stroke: transfer package of constraint induced movement therapy. Stroke. 2013;44(5):1383-8. doi:10.1161/STROKEAHA.111.000559

9. Gjersing L, Caplehorn JRM, Clausen T. Cross-cultural adaptation of research instruments: language, setting, time and statistical considerations. BMC Med Res Methodol. 2010;10(1):13. doi:10.1186/1471-2288-10-13

10. Beaton DE, Bombardier C, Guillemin F, Ferraz MB. Guidelines for the process of cross-cultural adaptation of self-report measures. Spine. 2000;25(24):3186-91. doi:10.1097/00007632-200012150-00014

11. Pasquali L. Princípios de elaboração de escalas psicológicas. Rev Psiq Clín. 1998;25:206-13.

12. Hiratuka E, Matsukura TS, Pfeifer L. Cross-cultural adaptation of the Gross Motor Function Classification System into Brazilian-Portuguese (GMFCS). Rev Bras Fisioter. 2010;14(6):537-44. doi:10.1590/S1413-35552010000600013
13. Terwee CB, Bot SDM, Boer MR, Windt DAWM, Knol DL, Dekker J et al. Quality criteria were proposed for measurement properties of health status questionnaires. J Clin Epidemiol. 2007;60(1):34-42. doi:10.1016/j.jclinepi.2006.03.012

14. Ferreira PL, Marques FB. Avaliação psicométrica e adaptação cultural e linguística de instrumentos de medicação em saúde: princípios metodológicos gerais. Coimbra: Centro de Estudos e Investigação em Saúde da Universidade de Coimbra; 1998.

15. Taub E, Griffin A, Uswatte G. Pediatric upper extremity motor activity log: revised (PMAL) manual. Birmingham: Pediatric Cl Therapy Research Group; 2012

16. Linacre JM. Investigating rating scale category utility. J Outcome Meas. 1993;3(2):103-22.

17. Atkinson G, Nevill AM. Statistical methods for assessing measurement error (reliability) in variables relevant to sports medicine. Sports Med. 1998;26(4):217-38. doi:10.2165/00007256-199826040-00002

18. Bland JM, Altman DG. Statistical methods for assessing agreement between two methods of clinical measurement. Lancet. 1986;1(8476):307-10. doi:10.1016/S0140-6736(86)90837-8

19. Rickards T, Sterling C, Taub E, Perkins-Hu C, Gauthier LV, Graham $M$ et al. Diffusion tensor imaging study of the response to constraint-induced movement therapy of children with hemiparetic cerebral palsy and adults with chronic stroke. Arch Phys Med Rehabil. 2014;95(3):506-14.e1. doi:10.1016/j.apmr.2013.08.245

20. Sterling C, Taub E, Davis D, Rickards T, Gauthier LV, Griffin A et al. Structural neuroplastic change after constraint-induced movement therapy in children with cerebral palsy. Pediatrics. 2013;31(5):1664-9. doi:10.1542/peds.2012-2051

21. Tieman BL, Palisano RJ, Gracely EJ, Rosenbaum PL. Gross motor capability and performance of mobility in children with cerebral palsy: a comparison across, home, school, and outdoors/community settings. Phys Ther. 2004;84(5):419-29.

22. DeLucca SC, Echols K, Ramey SL, Taub E. Pediatric constraint-induced movement therapy for a young child with cerebral palsy: two episodes of care. Physical Therapy. 2003;83(11):1003-13

23. Taub E, Griffin A, Nick J, Gammons K, Uswatte G, Law CR. Pediatric $\mathrm{Cl}$ therapy for stroke-induced hemiparesis in young children. Dev Neurorehabil. 2007;10(1):3-18. doi:10.1080/13638490601151836

24. Uswatte G, Taub E, Griffin A, Rowe J, Vogtle L, Barman J.Pediatric Arm Function Test: reliability and validity for assessing more-affected arm motor capacity in children with cerebral palsy. Am J Phys Med Rehabil. 2012;91(12):1060-9. doi:10.1097/PHM.0b013e318269ec76 